\title{
ДАЛЬНИЕ АСИНХРОННЫЕ СВЯЗИ В ДОЛГОПЕРИОДНЫХ КОЛЕБАНИЯХ КЛИМАТА МИРОВОГО ОКЕАНА И РЕГИОНАЛЬНОЙ АТМОСФЕРЫ ПРИМЕНИТЕЛЬНО К РЕСПУБЛИКЕ ТАТАРСТАН
}

\author{
Б. Г. Шерстюков, Ю. П. Переведенцев
}

\author{
Всероссийский Научно-исследовательский институт Гидрометеорологической Информаиии - \\ Мировой иентр Данных, Россия \\ Казанский (Приволжский) федеральный университет, Россия
}

Поступила в редакиию 19 декабря 2018 г.

\begin{abstract}
Аннотация: В статье рассматриваются результаты прогностической оценки изменений среднегодовой температуры воздуха в Казани в период 2019-2045 годы. Регрессионная модель построена с учетом существования дальних асинхронных связей в долгопериодных колебаниях температуры поверхности Мирового океана и температуры воздуха в республике Татарстан. В отличие от данных климатических моделей из проекта СМIP 5 по данным предложенной статистической модели ожидаются колебания температуры воздуха относительно средней величины $5,1^{\circ} \mathrm{C}$.
\end{abstract}

Ключевые слова: колебания климата, тренд, температура поверхности океана, дальние связи, прогностические оценки.

Abstract: The results of the prognostic assessment of changes in average annual air temperature in Kazan in the period 2019-2045 are considered. The regression model is constructed taking into account the existence of long-range asynchronous connections in long-term fluctuations of the surface temperature of the World Ocean and air temperature in the Republic of Tatarstan. In contrast to the data of climate models from the CMIP 5 project, according to the data of the proposed statistical model, air temperature fluctuations are expected relative to an average value of $5.1^{\circ} \mathrm{C}$.

Key words: climate oscillations, trend, ocean surface temperature, long-distance communications, prognostic assessment.

Метеорологические исследования в Казанском университете берут свое начало с момента публикации профессором Ф.К. Броннером в 1815 году научной статьи «Следствия из метеорологических наблюдений в Казани 1814 года», подготовленной на основании наблюдений, проводимых в Метеорологической обсерватории Казанского университета, основанной в 1812 году. Однако метеорологические ряды сохранились с 1828 года, которые используются при проведении климатических исследований. Из-за отсутствия стационарной метеорологической сети в начале XIX века исследования носили локальный характер. Исключение составляет статья профессора И. М. Симонова «О разности температуры в Южном и Северном полушарии», опубликованной в 1825 году. Астроном и геомагнитолог И. М. Симонов в период своего кругосветного путешествия (первая русская

(С Шерстюков Б. Г., Переведенцев Ю.П., 2019 антарктическая экспедиция Беллинсгаузена-Лазарева в 1819-1821 годов) провел многочисленные измерения атмосферного давления, температуры и влажности воздуха, что было положено в основу упомянутой статьи, возможно первой работы отечественных ученых на подобную тему [3].

Следует также отметить большую роль профессора А. Я. Купфера в становлении и развитии метеорологических и магнитных наблюдений в Казанском университете в начале XIX века, который после его избрания действительным членом Петербургской Академии наук, в 1829 году переезжает из Казани в Петербург. А. Я. Купфер является основателем Главной физической обсерватории в 1849 году (ныне Главная геофизическая обсерватория им. А. И. Воейкова). Он внес также значительный вклад в создание метеорологической службы в России, которой в 2019 году исполняется 185 лет. 


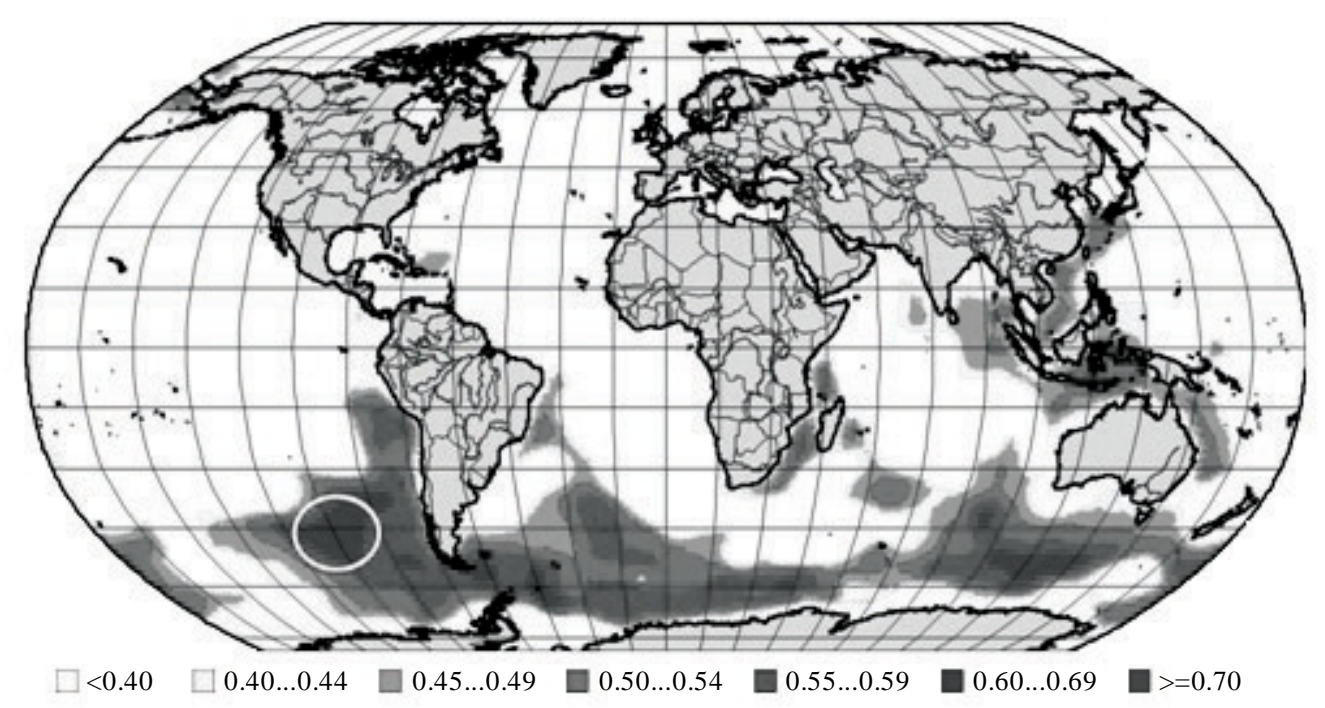

Puc. 1. Карта наилучших асинхронных коэффициентов корреляций ТПО в узлах с Тв в Казани

В современный период благодаря развитию информационно-вычислительных технологий и появлению открытого доступа к «Большим данным» тематика исследований Казанских метеорологов значительно расширилась. Появилась возможность исследовать структуру и динамику атмосферы до больших высот ( $\approx 80$ км), а климатические исследования проводить в глобальном и региональном плане. Основные результаты выполненных исследований опубликованы в ряде работ $[1,2,4-6,8,13]$. В связи с продолжающимся глобальным потеплением большой интерес представляют прогностические оценки будущих климатических изменений как на планете в целом, так и в его регионах. Открытый доступ к результатам ансамблевых расчетов, выполненных по большому количеству климатических моделей проекта СМІР $5 / 6$, позволяет оценивать изменения температуры воздуха до конца XXI века при различных сценариях выбросов парниковых газов. В частности, по данным работы [8] при наиболее «жестком» сценарии RCP 8.5 в Казани к концу нынешнего столетия среднеянварская температура может повыситься $\approx$ на $8^{\circ} \mathrm{C}$, а среднеиюльская $\approx$ на $5^{\circ} \mathrm{C}$. Следует отметить, что модельные расчеты имеют большой разброс и требуется находить среди множества моделей (их порядка 50) те, которые дают наиболее достоверные результаты при воспроизводстве прошлых климатических изменений. В частности, для Казани их оказалось 7 наиболее достоверных, что позволило оценить климатические проекции для сценариев RCP 2.6, 4.5, 8.5 до конца 21 века. При этом разброс оценок получается значительный.

В настоящей статье используется новый подход для оценки будущих изменений климата в Ка- зани. Он базируется на физико-статистическом учете дальних связей в долгопериодных колебаниях климата Мирового океана (температуры поверхности океана) и региональных колебаниях на континенте. Это направление во ВНИИГМИ-МЦД успешно развивается Б.Г. Шерстюковым, выпускником Казанского университета [7]. Физической основой данного исследования послужили следующие положения.

По данным [10] за 1961-2003 годы произошло увеличение теплосодержания климатической системы на $15,9 * 10^{22}$ джоулей. Из них увеличение теплосодержания океана произошло на $14,2 * 10^{22}$ джоулей, атмосферы - на $0,5 * 10^{22}$ джоулей, суши - на $0,76 * 10^{22}$ джоулей, льда - на $0,45^{*} 10^{22}$ джоулей. Из общего увеличения теплосодержания 89,3\% пришлось на океан и только 10,7\% - на все остальное (лед+суша+атмосфера). Увеличение теплосодержания атмосферы составило 3,1\% от общего увеличения теплосодержания всей климатической системы. Это означает, что в годы глобального потепления около $90 \%$ дополнительного тепла пошло на нагрев океанов, и только около $3 \%$ - на нагрев атмосферы. Эти $3 \%$ избыточного тепла привели к прямому нагреву атмосферы. Но тепло, получаемое Мировым океаном, не остается в нем навсегда, оно с некоторым запаздыванием передается в атмосферу, создавая отложенное на несколько лет потепление атмосферы. Так было всегда, поэтому можно ожидать, что сведения о состоянии океана в недалеком прошлом могут служить предикторами для оценок будущего состояния климата атмосферы.

Теплообмен между океаном и атмосферой происходит непрерывно, а его количественная оцен- 


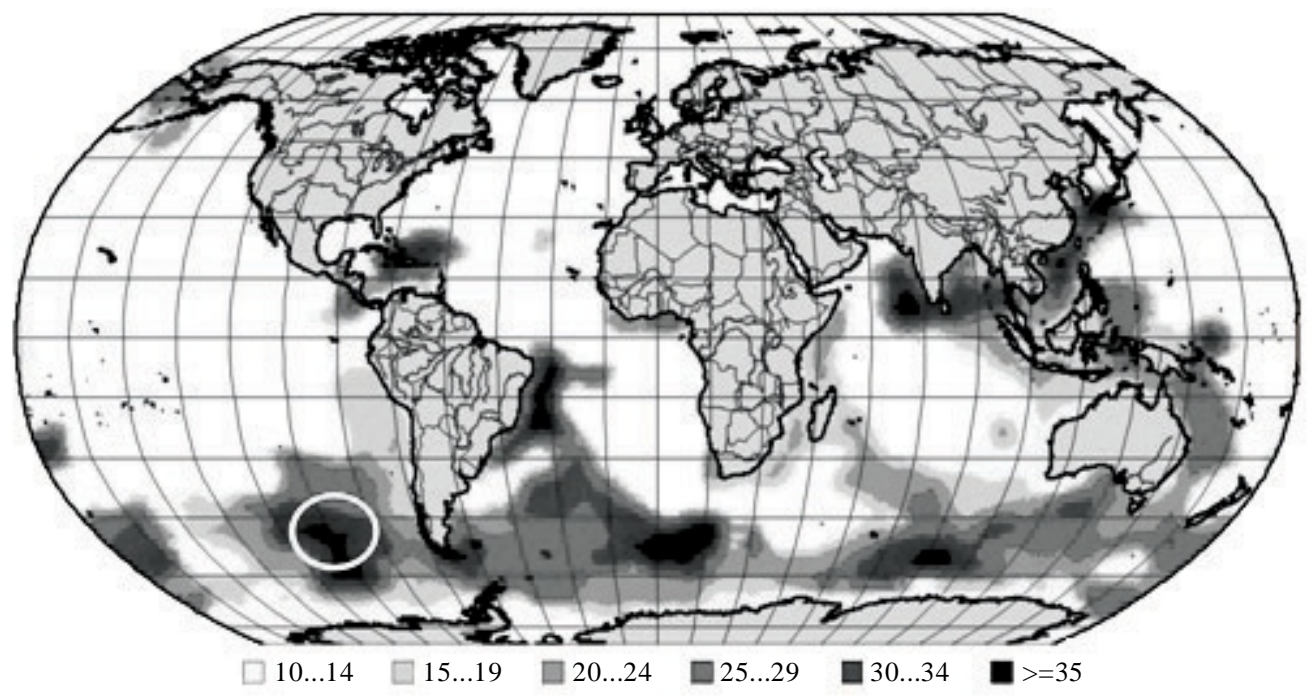

Puc. 2. Карта сдвигов временных рядов ТПО в узлах при наилучших асинхронных коэффициентах корреляций ТПО в этих узлах с Тв в Казани. Изменения Тв в Казани запаздывают относительно изменений ТПО в узлах

ка является непростой задачей. Глобальный конвейер океанических течений медленно переносит тепло из одних регионов и слоев в океане в другие по сложным, не совсем понятным траекториям. Как отмечает Лозье, уже ясна двумерная картина движения, но никак не трехмерная. Неясно, равномерно ли движется конвейер или он периодически меняет свою скорость, а главное - в какой степени связаны эти изменения скорости движения воды с изменениями климата и как изменения климата связаны с изменениями течений в Мировом океане. Идет дискуссия и о том, что является основным движителем конвейера - увеличение плотности воды, заставляющее ее тонуть, или же сильные ветры, заставляющие подниматься воду к поверхности [11].

Анализируя асинхронную ковариационную структуру климатических индексов, в публикации [14] описывается распространение колебаний по всему Северному полушарию через последовательность многократных превращений асинхронных атмосферно-океанических дальних связей. По оценкам тех же авторов, первоначальный сигнал изменения температуры в Северной Атлантике, распространяясь, достигает удаленных регионов полушария примерно 30 лет спустя. Тридцатилетнее запаздывание может послужить хорошей основой для прогностических оценок изменения климата на 30 лет.

\section{ИСХОДНЫЕ ДАННЫЕ}

В статье использовались данные наблюдений за температурой воздуха (ТВ) на метеорологической станции Казань за 1828-2016 годы, данные о температуре поверхности океана в узлах географической сетки $2 \times 2$ градуса широты и долготы за 1854-2016 годы $[9,12,15]$. Массив данных о температуре поверхности океана (ТПО) ERSST v3b представляет собой восстановленные ряды месячных аномалий температуры поверхности океана относительно норм за 1971-2000 годы. Восстановление пропущенных данных статистическими методами выполнено авторами массива. В отличие от версии ERSST v3, новая версия ERSST v3b не включает спутниковые данные, которые, как было установлено, вызывают слишком сильное смещение.

\section{МЕТОДЫ АНАЛИЗА И РЕЗУЛЬТАТЫ}

За 200 летнюю историю метеорологических наблюдений в Казани в изменениях среднегодовых значений температуры воздуха (Тв) можно обнаружить составляющие колебаний климата с разными частотами и тренд потепления. Исключим линейный тренд потепления, вычисленный по всему ряду. Полученные отклонения от тренда содержат многолетние колебания, которые предстоит исследовать и экстраполировать на будущее. Межгодовые колебания длительностью менее 3-х лет исключаем методом скользящих средних по 3-м точкам временного ряда.

Аналогичную обработку проделаем с рядами среднегодовой температуры поверхности океана (ТПО) в каждом узле Мирового океана. Дальние связи будем оценивать по асинхронным коэффициентам корреляции между ТПО в каждом отдельном узле географической сетки и Тв в Казани с запаздыванием Тв от 1 до 36 лет. В каждом исследуемом узле в серии асинхронных коэффициен- 


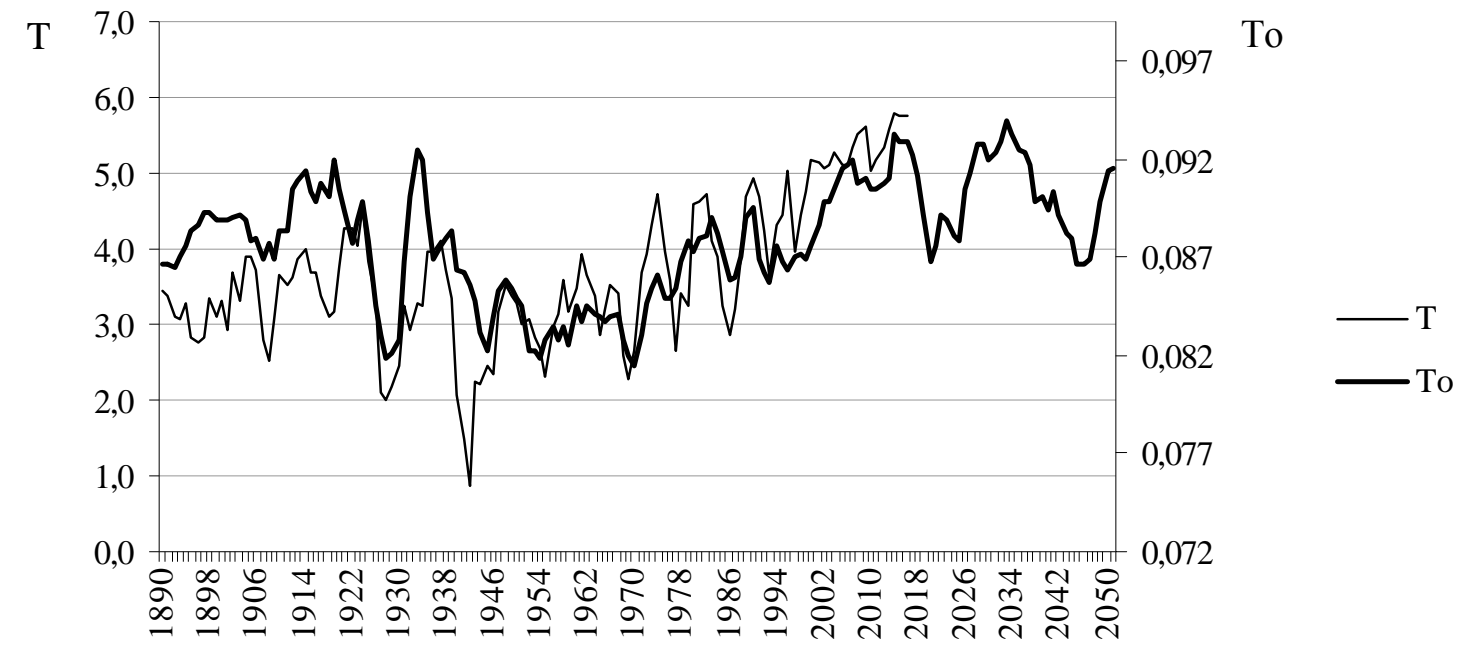

Годы

Puc. 3. Среднегодовая температура в Казани Т по данным наблюдений (сглажена по 3-летиям) и температура поверхности океана в районе пролива Дрейка со сдвигом на 35 лет

тов корреляции Тв с ТПО выделяем максимальный коэффициент корреляции и фиксируем величину запаздывания колебаний Тв, при которой обнаружена наилучшая корреляция. Если максимальный коэффициент корреляции $\mathrm{R}>$ 0,4 (вероятность случайности менее $1 \%$ ), то его значение наносится на карту. Одновременно на другую карту наносится величина запаздывания Тв в этом узле. После обработки данных во всех узлах географической сетки, строим карту наилучших асинхронных коэффициентов корреляции (рис. 1) и карту значений запаздывания колебаний Тв в Казани (рис. 2) относительно колебаний ТПО в каждом узле.

Анализ рисунка 1 показывает, что долгопериодные колебания Тв в Казани с высокой достоверностью повторяют те колебания ТПО, которые происходили в Южном океане в районе южного циркумполярного океанического течения Западных ветров. Нигде в Мировом океане больше нет мест со столь высокими корреляциями Тв Казани с ТПО в узлах.

Карта запаздываний колебаний (рис. 2) показывает, что отмеченные ранее наилучшие коэффициенты корреляции наблюдались в районе южного циркумполярного океанического течения при запаздывании Тв на время от 20 до 36 лет. Наибольший коэффициент корреляции $\mathrm{R}=0,69$ оказался в узле $106^{\circ}$ з.д. и $48^{\circ}$ ю.ш. при запаздывании Тв на 35 лет. На рисунках 1 и 2 регион наилучшей корреляции выделен белой окружностью.

На рисунке 3 показан график изменения среднегодовой температуры (Т) в Казани с 1890 по
2016 годы и температура поверхности океана (То) в узле $106^{\circ}$ 3.д., $48^{\circ}$ ю.ш. со сдвигом вперед на 35 лет. Рисунок 3 демонстрирует тесную асинхронную связь То и Т. Почти каждое колебание значений ряда То отражается в значениях Т.

Узел географической сетки $106^{\circ}$ з.д., $48^{\circ}$ ю.ш. находится на траектории океанического течения Западных ветров западнее пролива Дрейка, где океаническое течение пересекает южную оконечность подводного Восточно-Тихоокеанского поднятия в месте сужения течения перед проходом между южной оконечностью материка Южная Америка и Антарктическим полуостровом. Это место известно своими непрекращающимися штормами.

Широтная зона расположения течения Западных ветров является единственной зоной на Земле, в которой материки не преграждают путь океаническому течению на пути вокруг Земли. Узкое место вблизи пролива Дрейка со сложным рельефом дна способствует ускорению, завихрениям и глубокому интенсивному перемешиванию вод океана в этом районе. Это приводит к усиленному теплообмену между океаном и атмосферой. Возмущения в атмосфере, возникающие вблизи пролива Дрейка, в результате глобальной циркуляции океана и атмосферы и длительных неоднократных превращений на основе прямых и обратных атмосферно-океанических связей, через 35 лет достигают средних широт Европейской части России и, в частности, района республики Татарстан. Запаздывание примерно такое же как для Северного полушария отмечено в публикации [14]. 


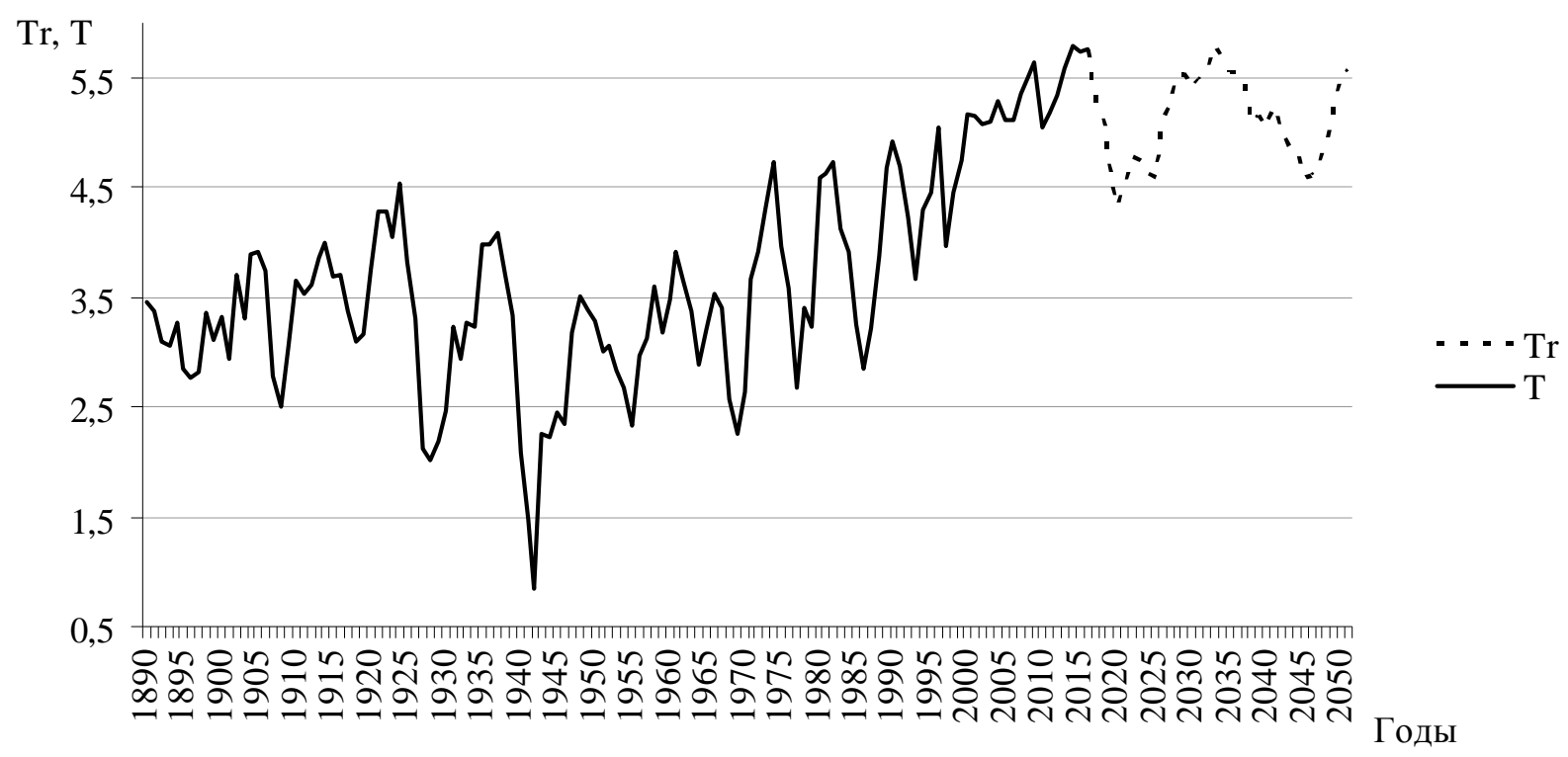

Puc. 4. Среднегодовая температура в Казани Т по данным наблюдений за 1890-2016 годы (сглажена по 3-летиям) и температура в Казани, вычисленная по уравнению регрессии на период до 2051 года (Tr)

Обнаруженные тесные асинхронные дальние связи подтверждаются исследованиями по другим регионам. Подобные результаты тесных асинхронных дальних связей, уже были описаны одним из авторов настоящей статьи [7] для центрального региона Европейской части России по данным станции Москва. Температура поверхности океана в далеком регионе на траектории течения Западных ветров оказалась наиболее важным элементом асинхронных корреляций с температурой воздуха в обоих регионах Европы.

\section{ПРОГНОСТИЧЕСКИЕ ОЦЕНКИ}

Распространенные подходы построения сценариев изменения климата на основе физико-математического моделирования строятся на предположении о ведущей роли в климате усиления парникового эффекта при увеличении количества антропогенного углекислого газа в атмосфере, начало интенсивного увеличения которого датируется 1970-ми годами. График рисунка 3 показывает, что на рассматриваемом интервале самым холодным был 1942 год, после которого началось потепление, продолжающееся до настоящего времени. Потепление в Казани началось за три десятилетия до начала интенсивного увеличения антропогенных выбросов в атмосферу. В 1970 годы ускорения потепления не наблюдалось. Явное несоответствие прогнозных оценок по упомянутым моделям дает основание для поиска альтернативных подходов к прогностическим оценкам ожидаемых изменений климата. Учитывая обнаруженные тесные асинх- ронные связи климата Татарстана с процессами в глобальном океане, можно предложить регрессионный подход построения прогностической траектории ожидаемого состояния климата Татарстана.

Обнаруженная тесная асинхронная корреляция позволяет строить регрессионное уравнение со сдвигом на 35 лет для вычисления прогностических оценок долгопериодных изменений Тв в Казани на предстоящие 35 лет.

Итак, с учетом сдвига запаздывания строим уравнение регрессии Тв в Казани от ТПО в выделенном узле в районе пролива Дрейка по данным на интервале 1890-2016 годов. Предиктором в уравнении является ТПО со сдвигом вперед на 35 лет, а предиктантом будет Тв в Казани. После сдвига значений ТПО получаем значения предиктора до 2051 года. По уравнению вычисляем ожидаемые изменения Тв в Казани на предстоящие 35 лет. Возвращаем тренд Тв, исключенный на первом этапе анализа и получаем прогностические оценки Тв в Казани на период до 2051 года (рис. 4).

На рисунке 4 видно, что с 1941 по 1969 год были самые холодные годы со средней температурой около $3^{\circ} \mathrm{C}$. Далее температура волнообразно повышалась и в последние 16 лет составила около $5^{\circ} \mathrm{C}$. Вычисленные по уравнению регрессии прогностические значения показывают, что в предстоящие 35 лет будут происходить колебания температуры в Казани около среднего значения $5,1^{\circ} \mathrm{C}$. Если $5,1^{\circ} \mathrm{C}$ принять за новую прогностическую норму, тогда, судя по графику, с учетом колебаний, в 2019-2025 годы температура будет ниже прогнос- 
тической нормы на $0,3-0,5^{\circ} \mathrm{C}$, а в 2028-2037 годы поднимется выше этой нормы на $0,4 \div 0,5^{\circ} \mathrm{C}$. К 2045 году температура опять станет ниже нормы на $0,3 \div 0,4^{\circ} \mathrm{C}$.

Таким образом, исследования показали, что долгопериодные колебания Тв в Казани в значительной мере являются следствием глобальных изменений в климатической системе, истоки которых находятся в особом регионе взаимодействия атмосферы с Южным океаном вблизи пролива Дрейка. Это регион, где интенсивность взаимодействия атмосферы с океаном усилена естественными физико-географическими условиями, сформированными южным циркумполярным океаническим течением и относительно узким проливом между двумя континентами.

Возмущения на границе океан-атмосфера в результате многократной цепочки асинхронных атмосферно-океанических связей и общей циркуляции океана и атмосферы распространяются в другие регионы Земли и достигают Казани через 35 лет. Выявленная задержка в передаче возмущений позволила построить асинхронное уравнение регрессии с возможностью вычисления долгопериодных прогностических колебаний температуры в Казани на предстоящие десятилетия.

В предстоящие 35 лет ожидается стабилизация климата Казани со среднегодовой температурой около $5,1^{\circ} \mathrm{C}$ и с колебаниями относительно этого значения на $\pm 0,3 \div 0,5^{\circ} \mathrm{C}$. Относительно холодными ожидаются 2019-2025 годы, а теплыми ожидаются 2028-2037 годы.

Работа выполнена при финансовой поддержке Российского фонда фундаментальных исследований, проекты 18-05-00721 и 18-45-160006.

\section{СПИСОК ЛИТЕРАТУРЫ}

1. Климатические условия и ресурсы республики Татарстан / Ю. П. Переведенцев [ и др.]. - Казань : Издательство Казанского университета, 2008. - 288 с.

2. Особенности проявления современного потепления климата в тропосфере Атлантико-Европейского региона / Ю. П. Переведенцев [ и др.] // Метеорология и гидрология. - 2004. - № 2. - С. 38-47.

3. Переведенцев Ю. П. Метеорология в Казанском университете: становление, развитие, основные достижения / Ю. П. Переведенцев. - Казань : Издательство Казанского университета, 2001. - 128 с.

4. Переведенцев Ю. П. Оценка современных изменений температуры воздуха и скорости ветра в тропосфере Северного полушария / Ю. П. Переведенцев, К. М. Шанталинский // Метеорология и гидрология. 2014. - № 10. - С. 19-31.
5. Современные тенденции изменения климата в Приволжском федеральном округе / Ю. П. Переведенце [ и др.] // Георесурсы. - 2012. - № 6(48). - С. 19-24.

6. Факторный анализ многолетней динамики глобального термического режима приземного слоя воздуха / М. А. Верещагин [ и др.] // Известия Российской академии наук. Сер. географическая. - 2004. - № 5. C. 34-41.

7. Шерстюков Б. Г. Асинхронные связи температуры воздуха в Центральном регионе России с температурой поверхности мирового океана / Б. Г. Шерстюков // Труды ВНИИГМИ-МЦД. - 2019. - Вып. 184.

8. Empirical Statistical Model of Climatic Changes in the Volga Region / Y.P. Perevedentsev [et al.] // IOP Conference Series: Earth and Environmental Science. 2018. - Vol. 211, No. 1. - Art: 012016.

9. Improvements NOAAs Historical Merged LandOcean Temp Analysis (1880-2006) / T. M. Smith [et al.] // Journal of Climate. - 2008. - Vol. 21 . - P. 2283-2296.

10. IPCC (2013). Climate Change 2013: The Physical Science Basis. Contribution of Working Group I to the Fifth Assessment Report of the Intergovernmental Panel on Climate Change / T. F. Stocker [et al.]. - Cambridge, United Kingdom; New York, USA. - 1535 p. - DOI: 10.1017/ CBO9781107415324.

11. Lozier M. S. Deconstructing the Conveyor Belt / M. S. Lozier // Science. - 2010. - Vol. 328. - P. 1507-1511.

12. The Extended Reconstructed Sea Surface Temperature (ERSST) dataset is a global monthly sea surface temperature analysis derived from the International Comprehensive Ocean-Atmosphere Dataset. - URL: https:/ /www.ncdc.noaa.gov/data-access/marineocean-data/ extended-reconstructed-sea-surface-temperature-ersst-v3b.

13. Thermodynamic Parameter Variations in the Troposphere and Stratosphere in 1979-2016 / Y. P. Perevedentsev [et al.] // IOP Conference Series: Earth and Environmental Science. - 2018. - Vol. 211, No. 1. Art: 012015.

14. Wyatt M. G. Atlantic multidecadal oscillation and Northern hemisphere's climate variability / M. G. Wyatt, S. Kravtsov, A. A. Tsonis // Climate Dynamics. - 2012. Vol. 38, Iss. 5-6. - P. 929-949.

15. Xue Y. Interdecadal changes of 30-Yr SST Normals during 1871-2000 / Y. Xue, T. M. Smith, R. W. Reynolds / / Journal of Climate. - 2003. - Vol. 16. - P. 1601-1612.

\section{REFERENCES}

1. Klimaticheskiye usloviya i resursy respubliki Tatarstan / YU. P. Perevedentsev [ i dr.]. - Kazan' : Izdatel'stvo Kazanskogo universiteta, 2008. - 288 s.

2. Osobennosti proyavleniya sovremennogo potepleniya klimata v troposfere Atlantiko-Evropeyskogo regiona / YU. P. Perevedentsev [ i dr.] // Meteorologiya i gidrologiya. - 2004. - № 2. - S. 38-47.

3. Perevedentsev YU. P. Meteorologiya v Kazanskom universitete: stanovleniye, razvitiye, osnovnyye dostizhe- 
Дальние асинхронные связи в долгопериодных колебаниях климата Мирового океана и региональной атмосферы применительно креспублике Татарстан

niya / YU. P. Perevedentsev. - Kazan' : Izdatel'stvo Kazanskogo universiteta, 2001. - $128 \mathrm{~s}$.

4. Perevedentsev YU. P. Otsenka sovremennykh izmeneniy temperatury vozdukha i skorosti vetra $\mathrm{v}$ troposfere Severnogo polushariya / YU. P. Perevedentsev, K. M. SHantalinskiy // Meteorologiya i gidrologiya. - 2014. - № 10. - S. 19-31.

5. Sovremennyye tendentsii izmeneniya klimata $v$ Privolzhskom federal'nom okruge / YU. P. Perevedentse [ i dr.] // Georesursy. - 2012. - № 6(48). - S. 19-24.

6. Faktornyy analiz mnogoletney dinamiki global'nogo termicheskogo rezhima prizemnogo sloya vozdukha / M. A. Vereshchagin [ i dr.] // Izvestiya Rossiyskoy akademii nauk. Ser. geograficheskaya. - 2004. - № 5. - S. 34-41.

7. SHerstyukov B. G. Asinkhronnyye svyazi temperatury vozdukha $v$ TSentral'nom regione Rossii s temperaturoy poverkhnosti mirovogo okeana / B. G. SHerstyukov // Trudy VNIIGMI-MTSD. - 2019. - Vyp. 184.

8. Empirical Statistical Model of Climatic Changes in the Volga Region / Y.P. Perevedentsev [et al.] // IOP Conference Series: Earth and Environmental Science. - 2018. - Vol. 211, No. 1. - Art: 012016.

9. Improvements NOAAs Historical Merged LandOcean Temp Analysis (1880-2006) / T. M. Smith [et al.] // Journal of Climate. - 2008. - Vol. 21. - P. 2283-2296.

Шерстюков Борис Георгиевич

доктор географических наук, заведующий лабораторией исследования последствий изменения климата Всероссийского научно-исследовательского института гидрометеорологической информации - Мирового Центpa Данных, г. Обнинск, E-mail: boris@ meteo.ru

Переведенцев Юрий Петрович

доктор географических наук, профессор, заведующий кафедрой метеорологии, климатологии и экологии атмосферы Института экологии и природопользования Казанского (Приволжского) федерального университета, г. Казань, E-mail: ypereved@pkfu.ru
10. IPCC (2013). Climate Change 2013: The Physical Science Basis. Contribution of Working Group I to the Fifth Assessment Report of the Intergovernmental Panel on Climate Change / T. F. Stocker [et al.]. - Cambridge, United Kingdom; New York, USA. - 1535 p. - DOI: 10.1017/ CBO9781107415324.

11. Lozier M. S. Deconstructing the Conveyor Belt / M. S. Lozier // Science. - 2010. - Vol. 328. - P. 1507-1511.

12. The Extended Reconstructed Sea Surface Temperature (ERSST) dataset is a global monthly sea surface temperature analysis derived from the International Comprehensive Ocean-Atmosphere Dataset. - URL: https:// www.ncdc.noaa.gov/data-access/marineocean-data/extended-reconstructed-sea-surface-temperature-ersst-v $3 b$.

13. Thermodynamic Parameter Variations in the Troposphere and Stratosphere in 1979-2016 / Y. P. Perevedentsev [et al.] // IOP Conference Series: Earth and Environmental Science. - 2018. - Vol. 211, No. 1. - Art: 012015.

14. Wyatt M. G. Atlantic multidecadal oscillation and Northern hemisphere's climate variability / M. G. Wyatt, S. Kravtsov, A. A. Tsonis // Climate Dynamics. - 2012. Vol. 38, Iss. 5-6. - P. 929-949.

15. Xue Y. Interdecadal changes of 30-Yr SST Normals during 1871-2000 / Y. Xue, T. M. Smith, R. W. Reynolds // Journal of Climate. - 2003. - Vol. 16. - P. 16011612.

Sherstyukov Boris Georgievitch

Doctor of Geographical Sciences, Head of the Laboratory of Climate Change Impact Research, All-Russian Research Institute of Hydrometeorological Information - World Data Centre, Obninsk, E-mail: boris@meteo.ru

Perevedentsev Yuriy Petrovitch

Doctor of Geographical Sciences, Professor, Head of the Department of meteorology, climatology and atmosphere ecology, Institute of the Institute of Environmental Sciences, Kazan (Volga) Federal University, Kazan, E-mail: ypereved@pkfu.ru 